Supporting information

\title{
Synthesis and Characterization of Novel Organic Heteroatom Compounds from Reaction of Woollins' Reagent with Various Organic Substrates
}

Guoxiong Hua, Junyi Du, David B. Cordes, Kasun S. A. Arachchige, Alexandra M. Z. Slawin and J. Derek Woollins*

${ }^{1} \mathrm{H}$ and ${ }^{13} \mathrm{C}$ NMR data of compounds $2,4,6,8,9,10$ and 13:

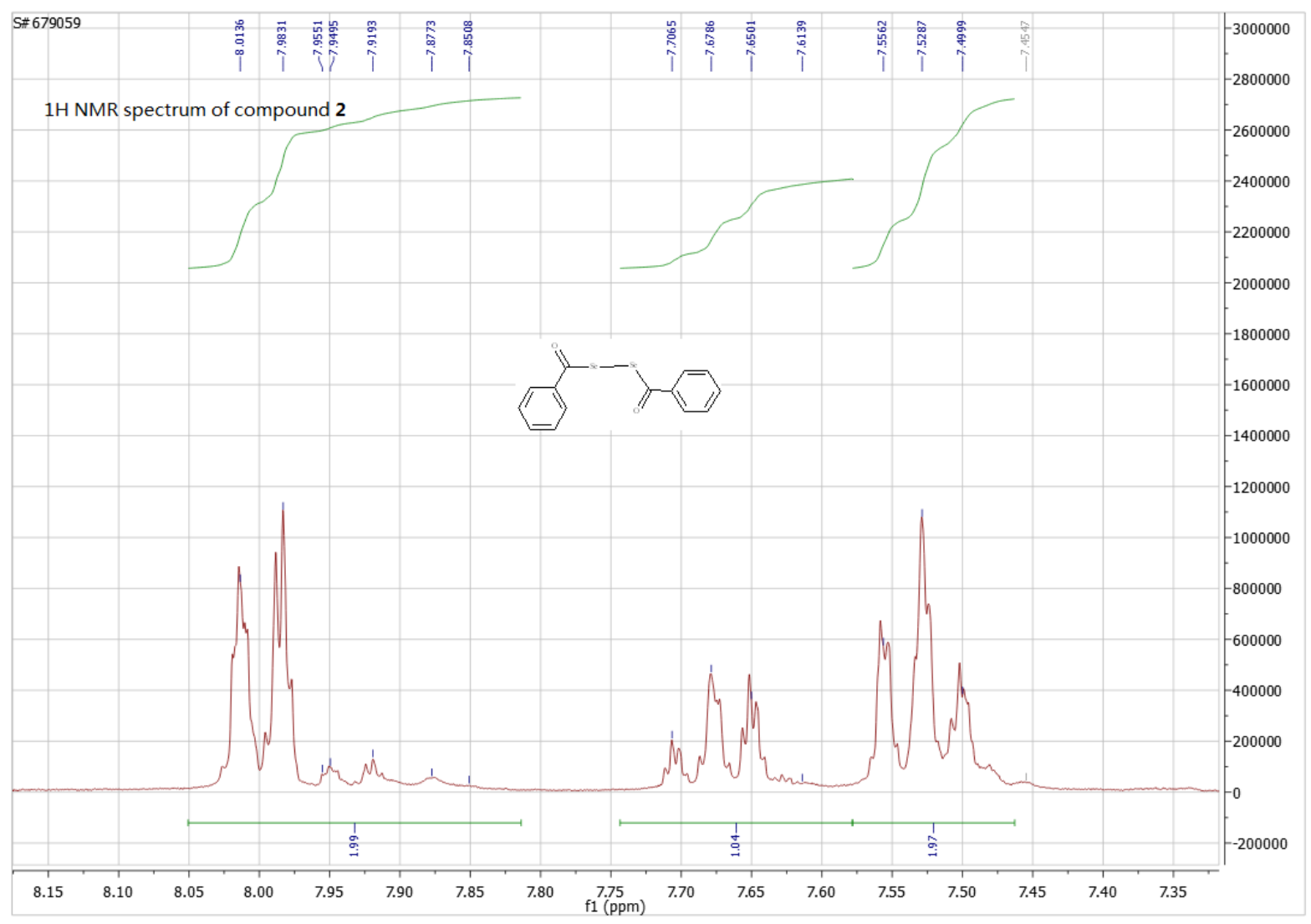




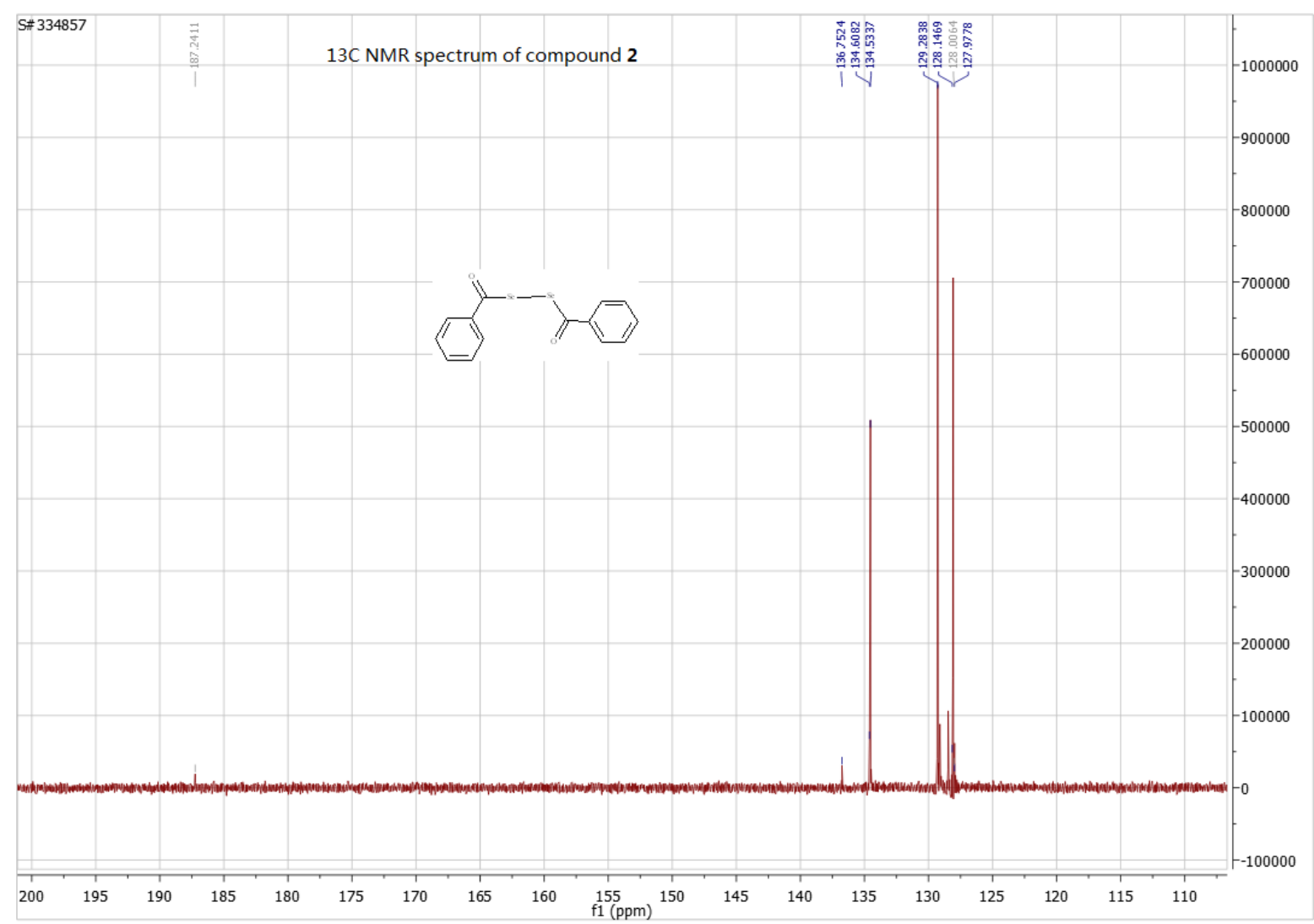




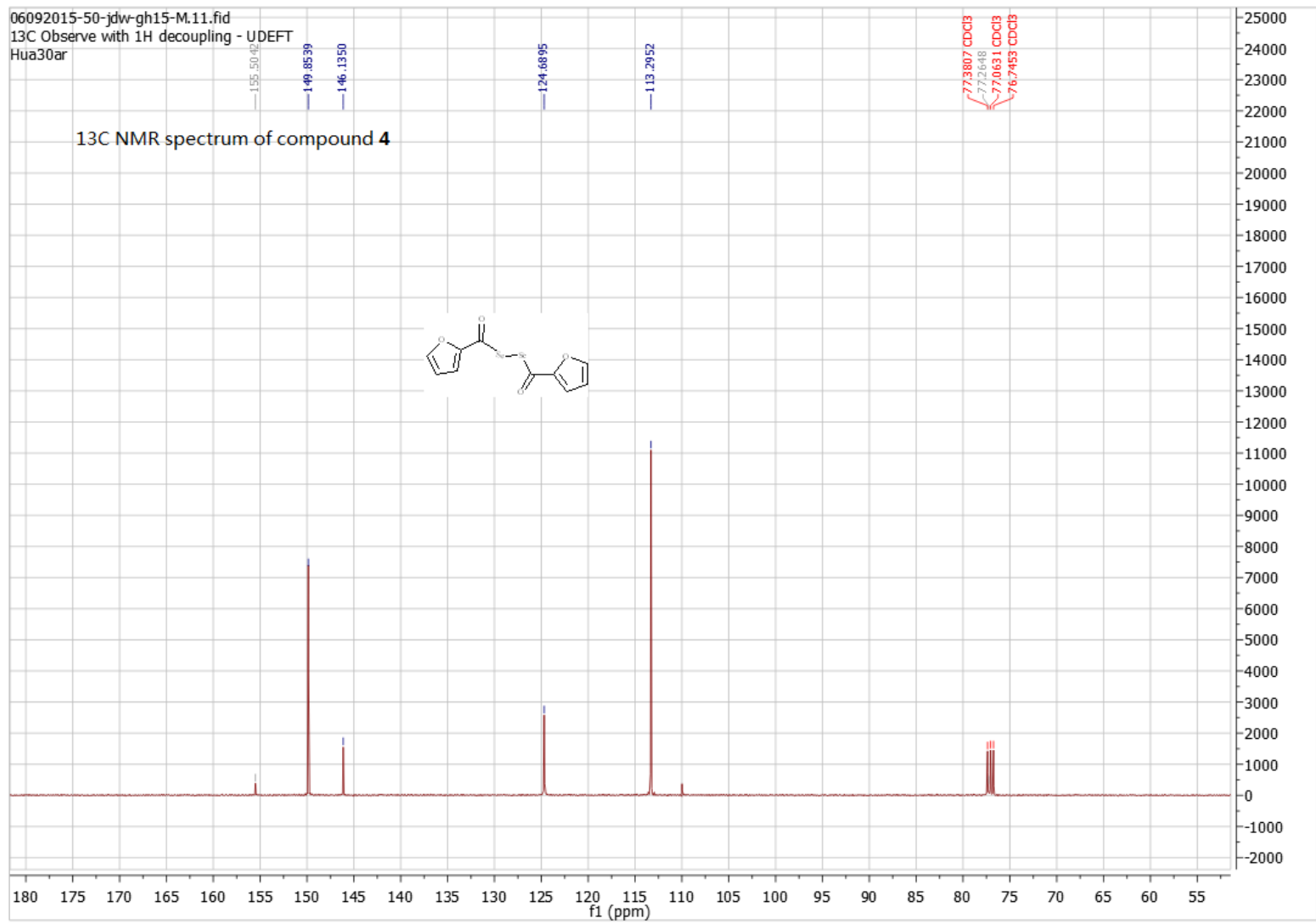




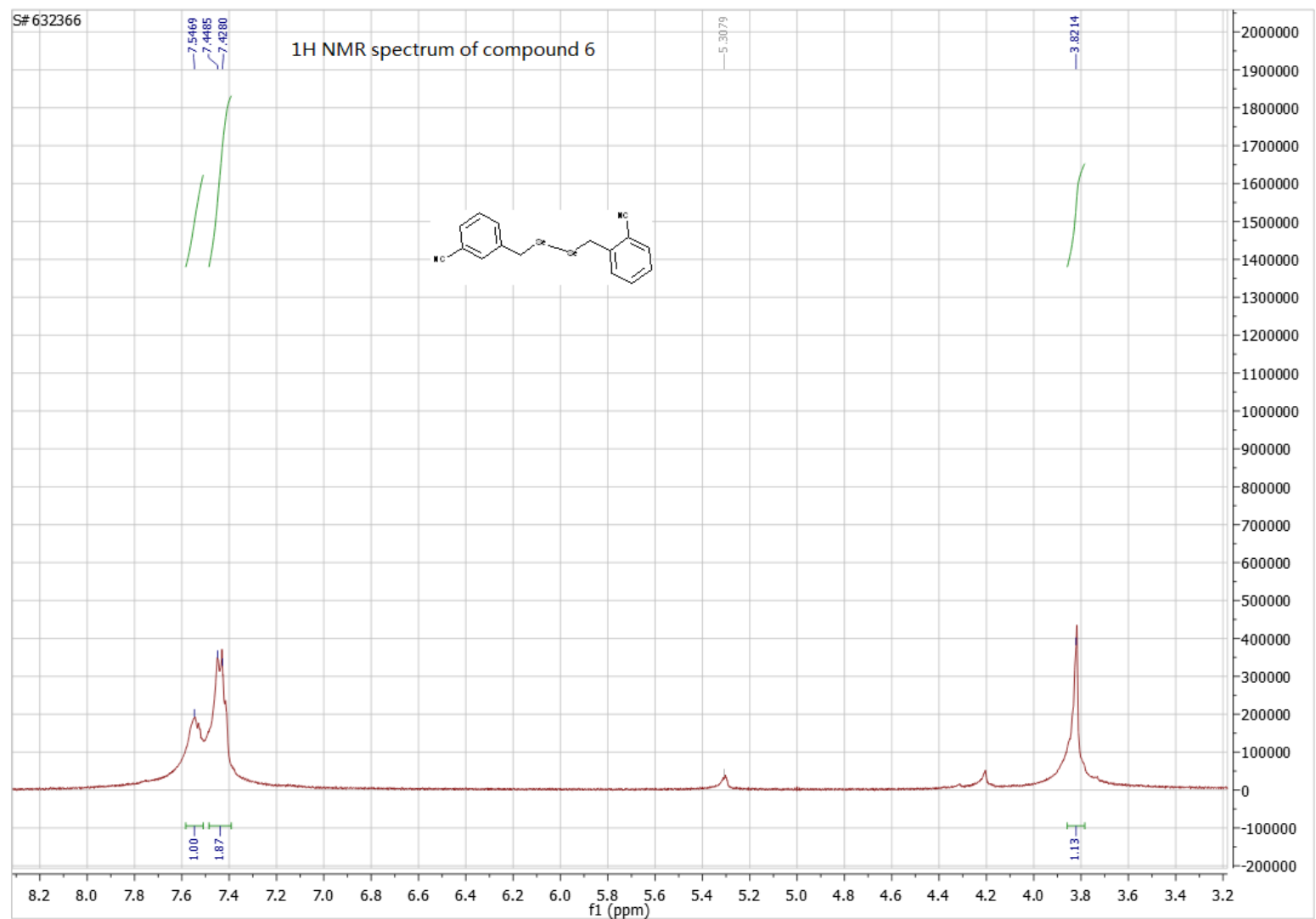




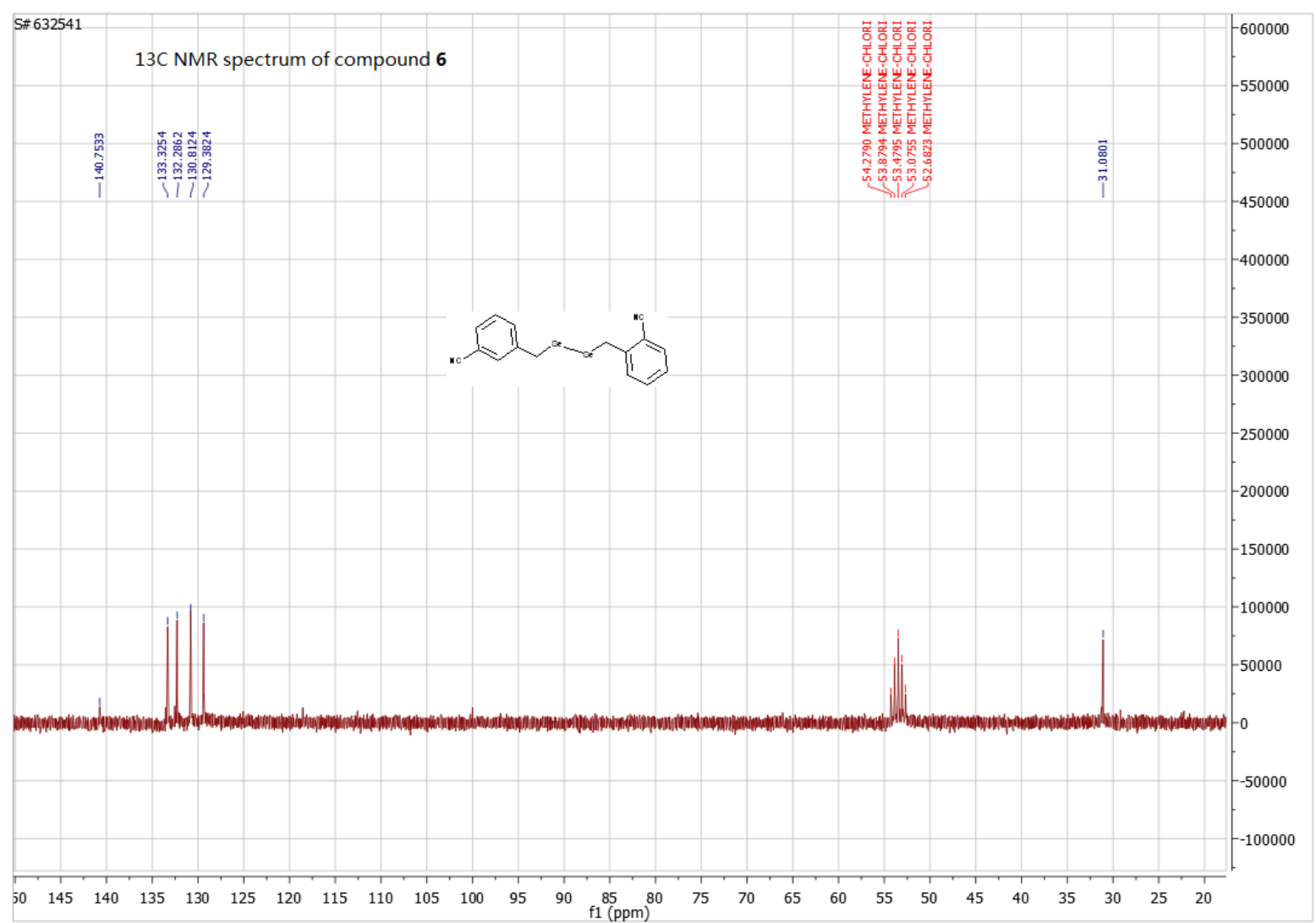




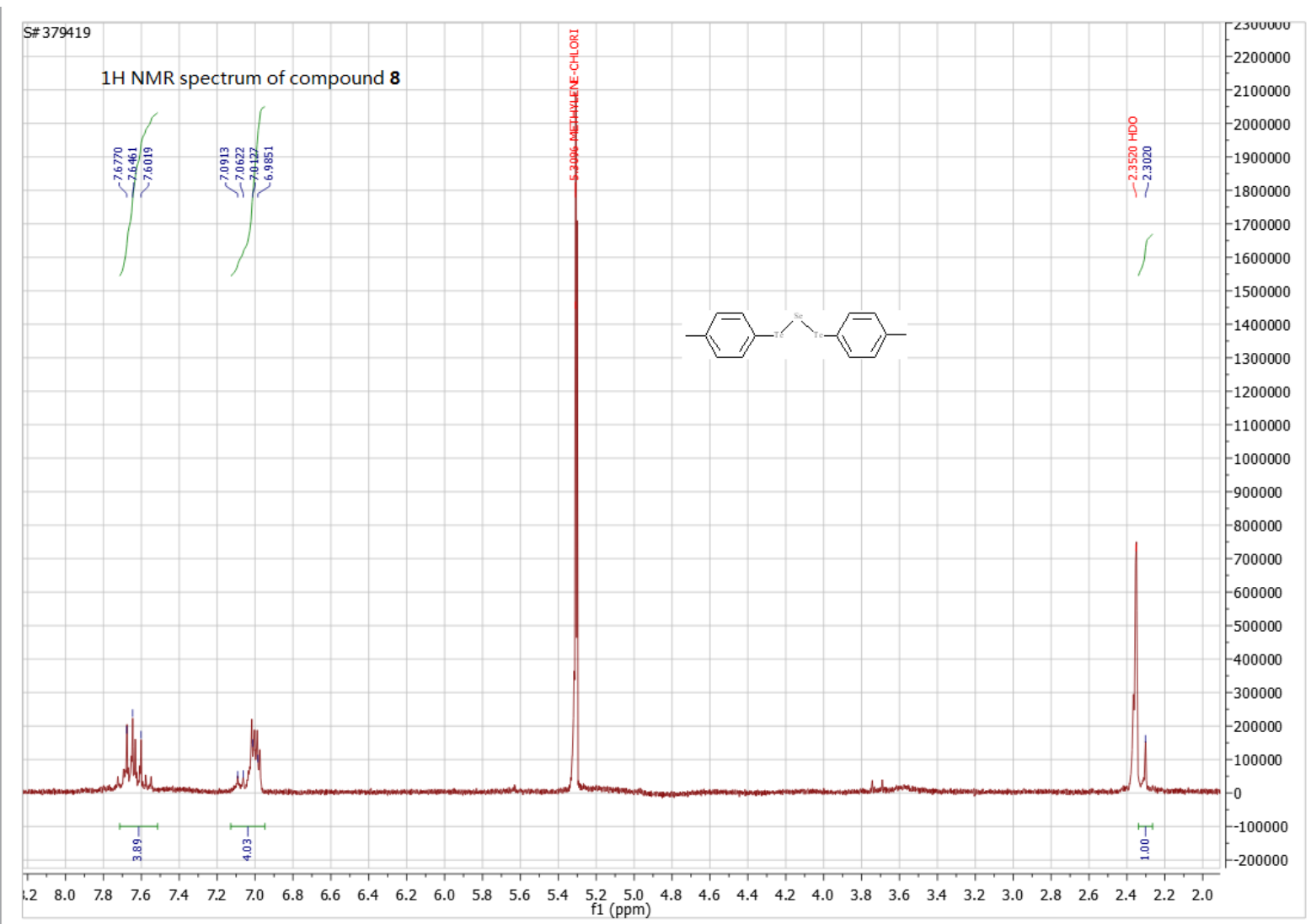




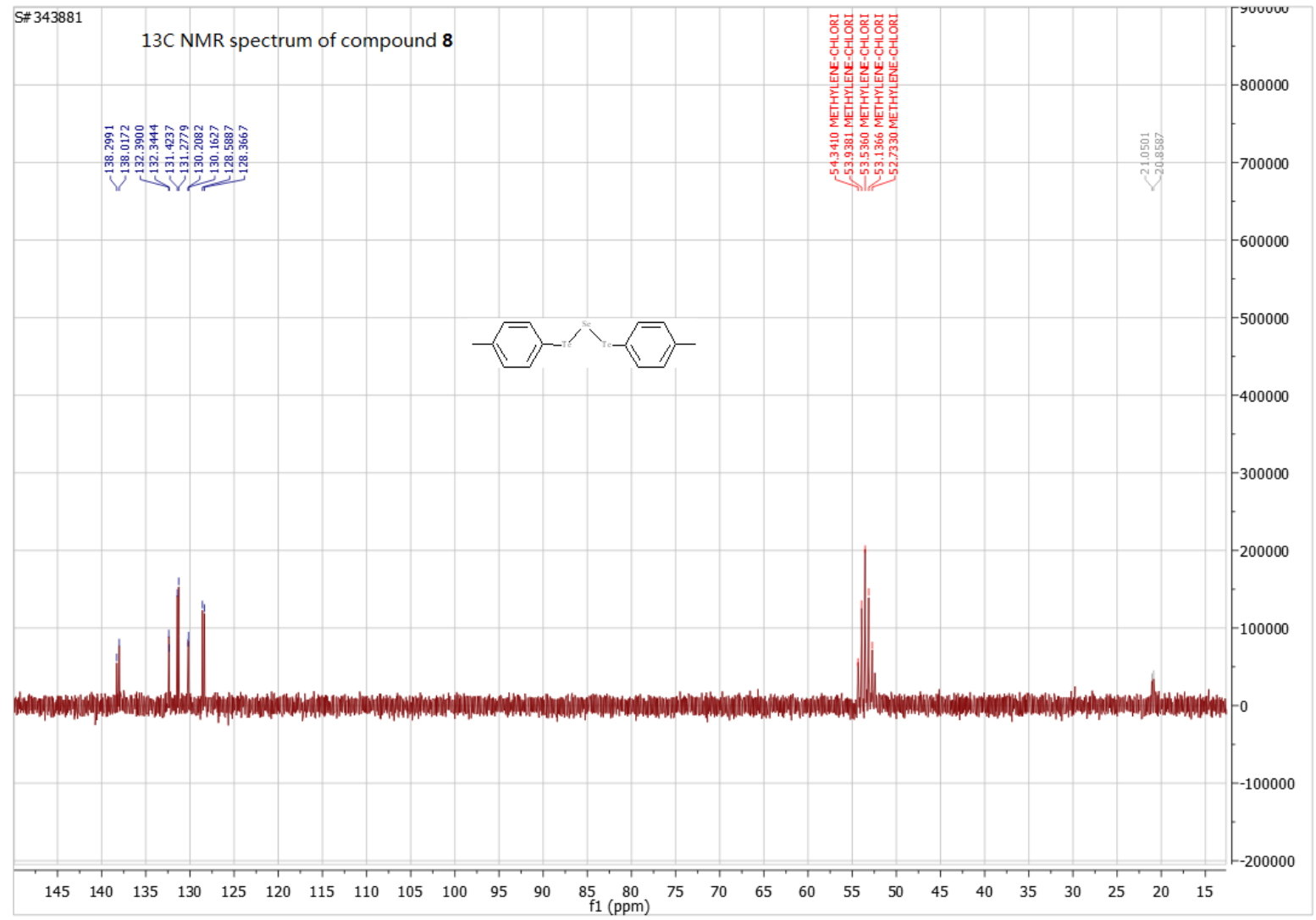




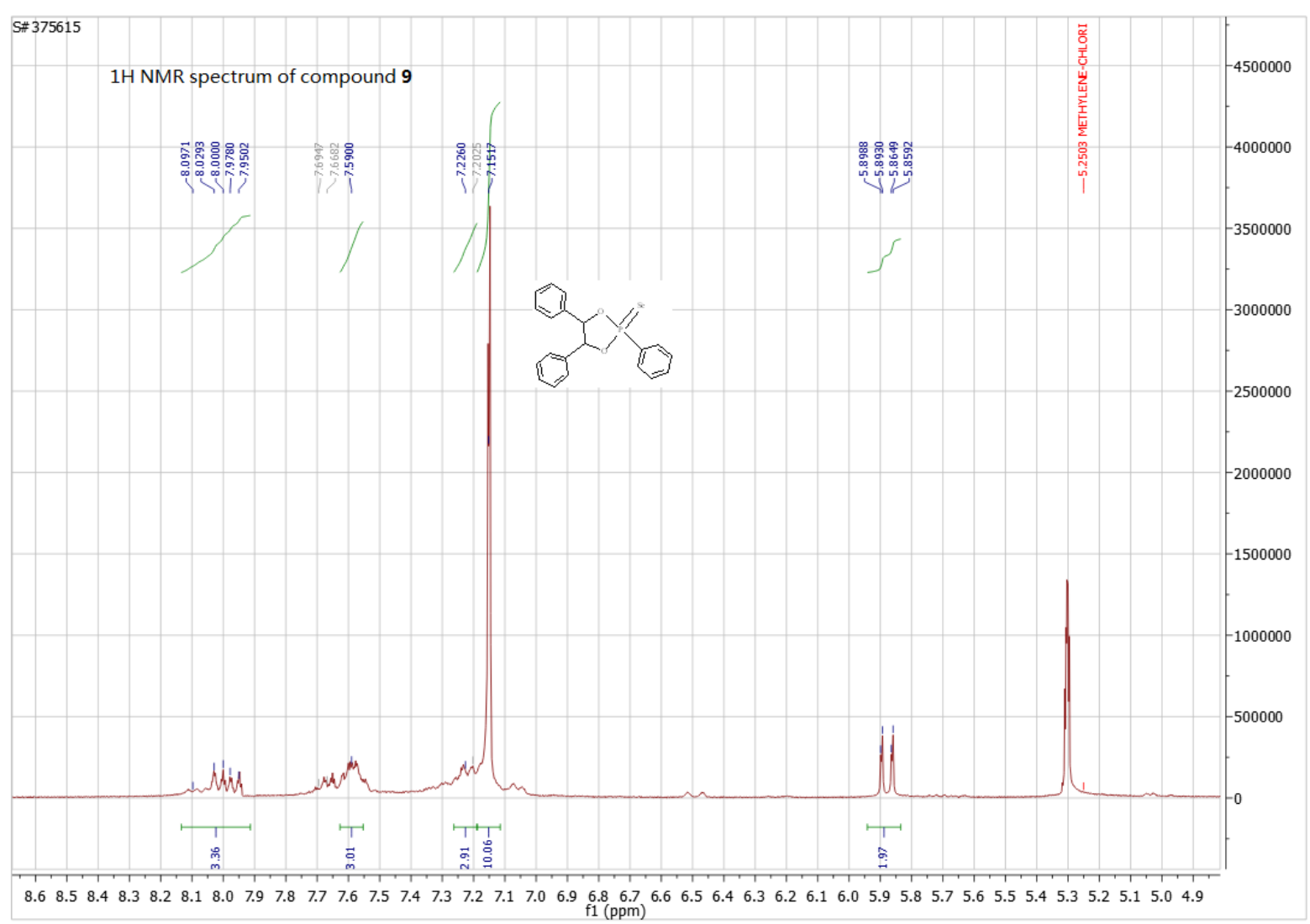




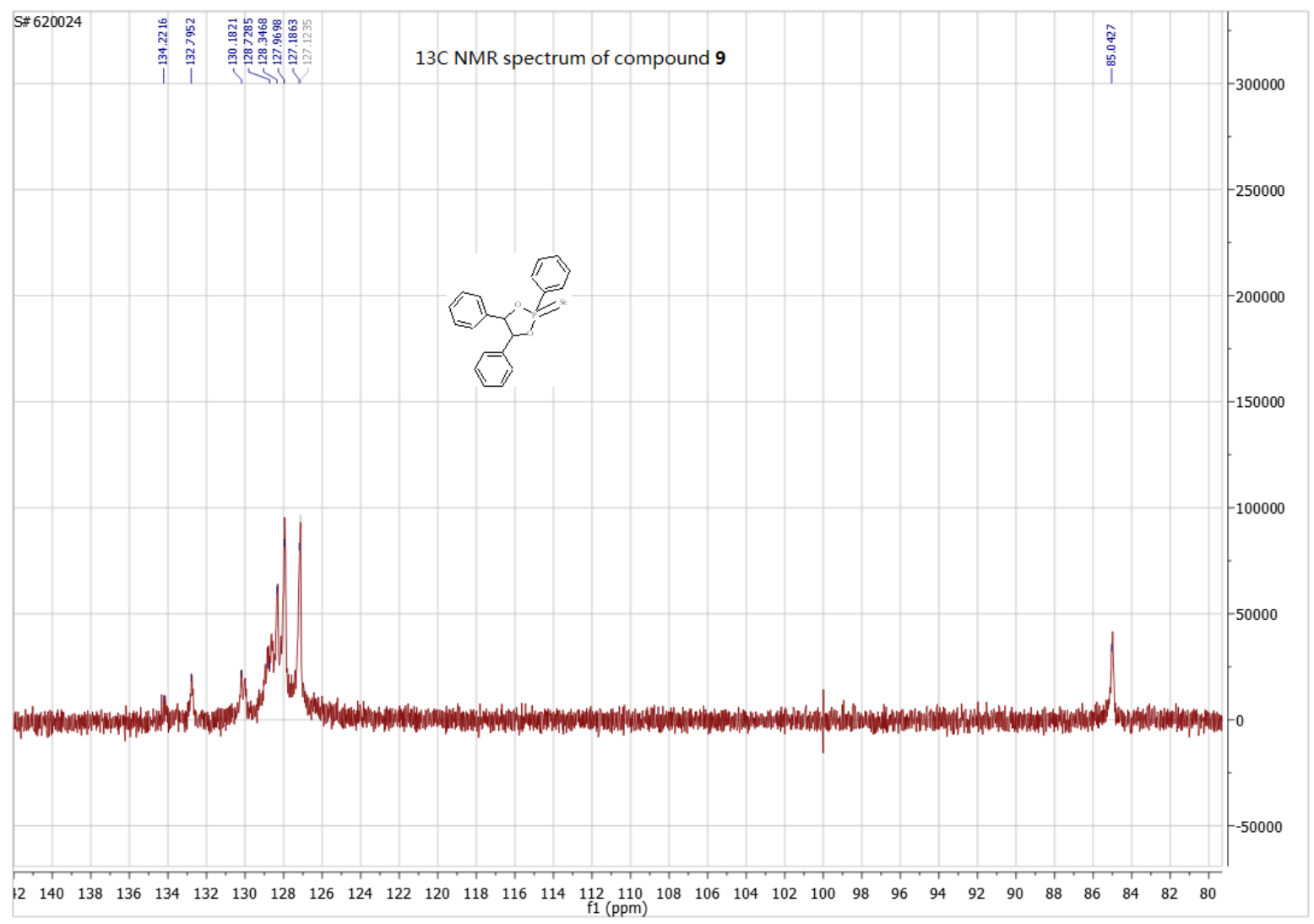




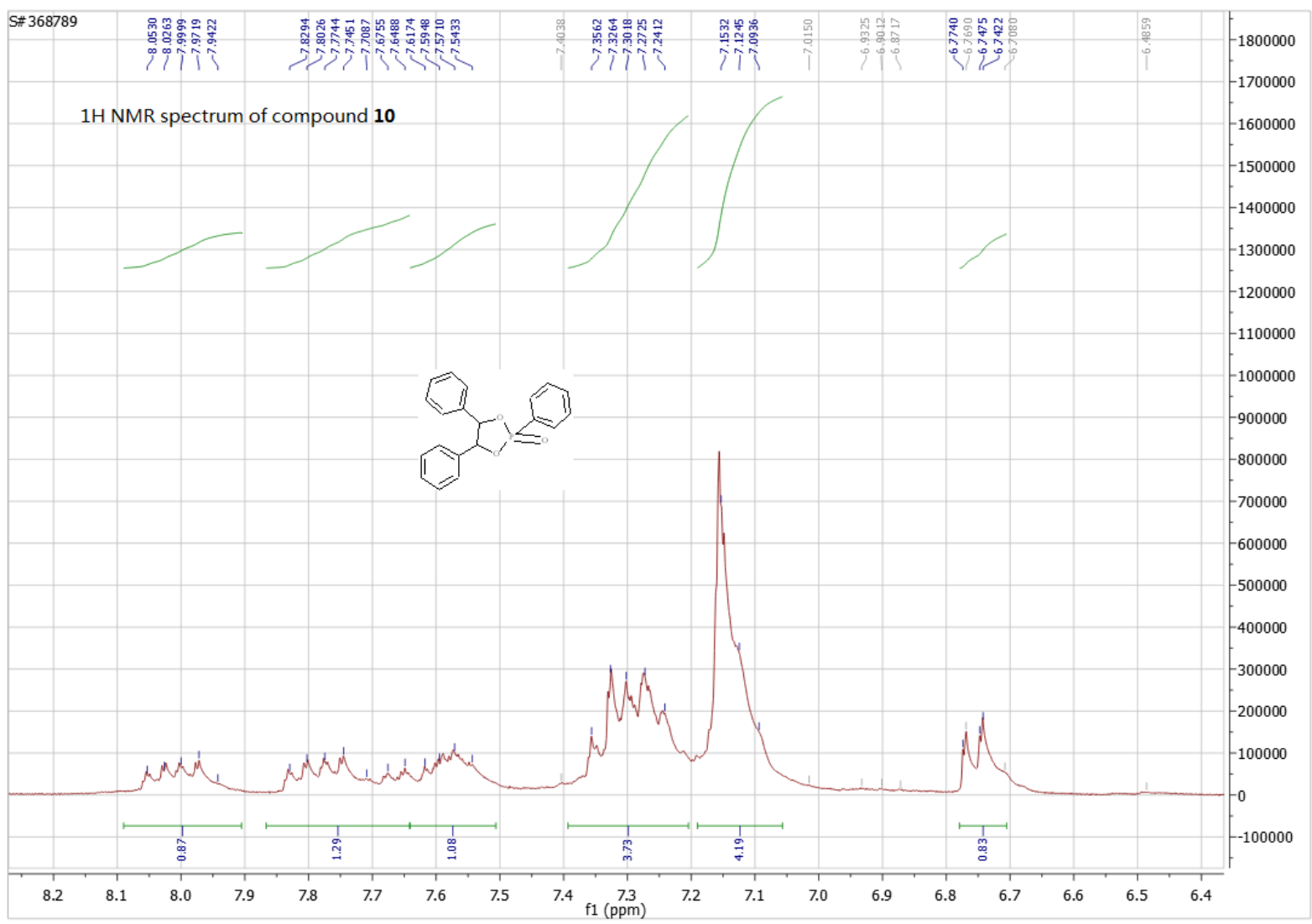




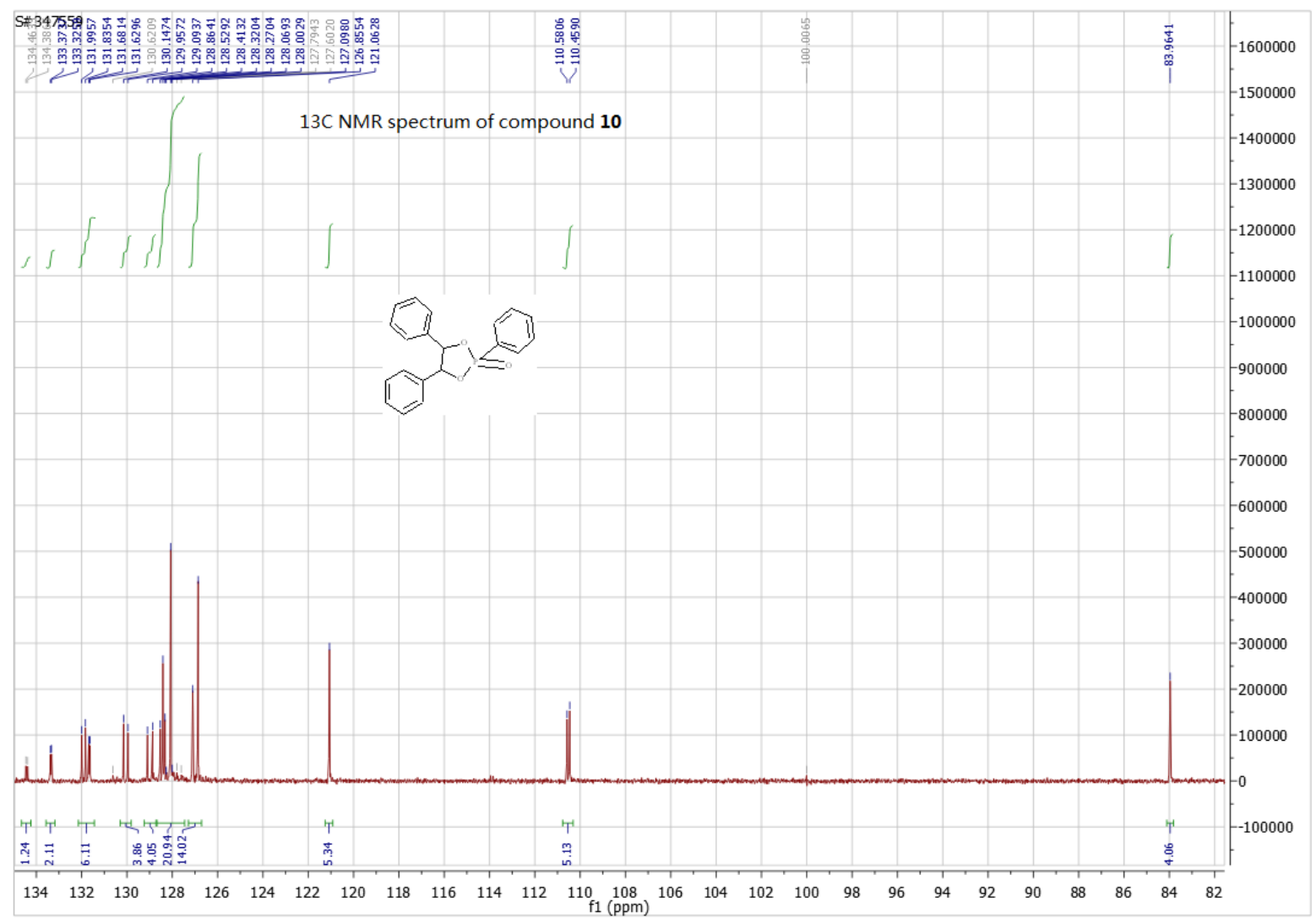




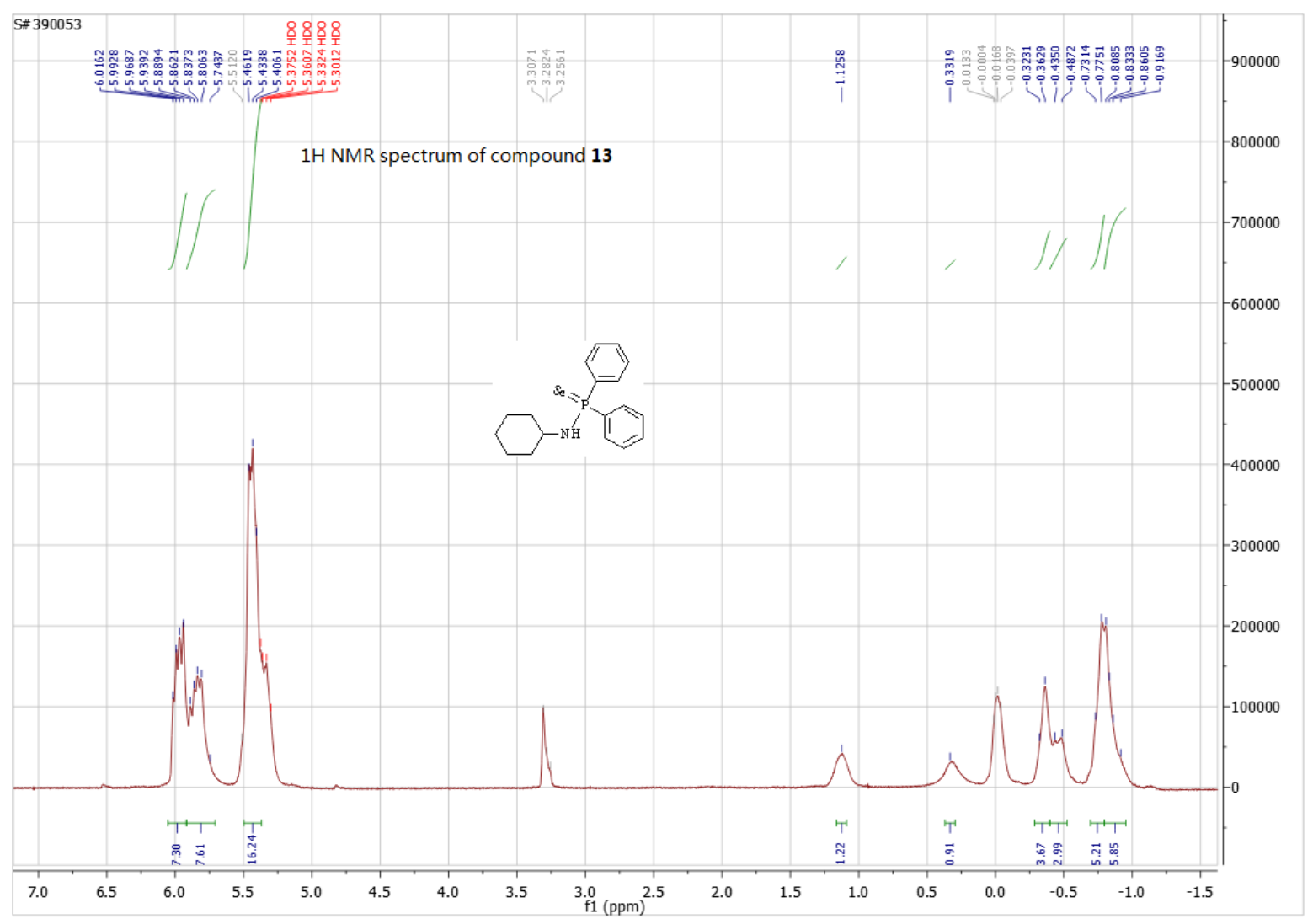




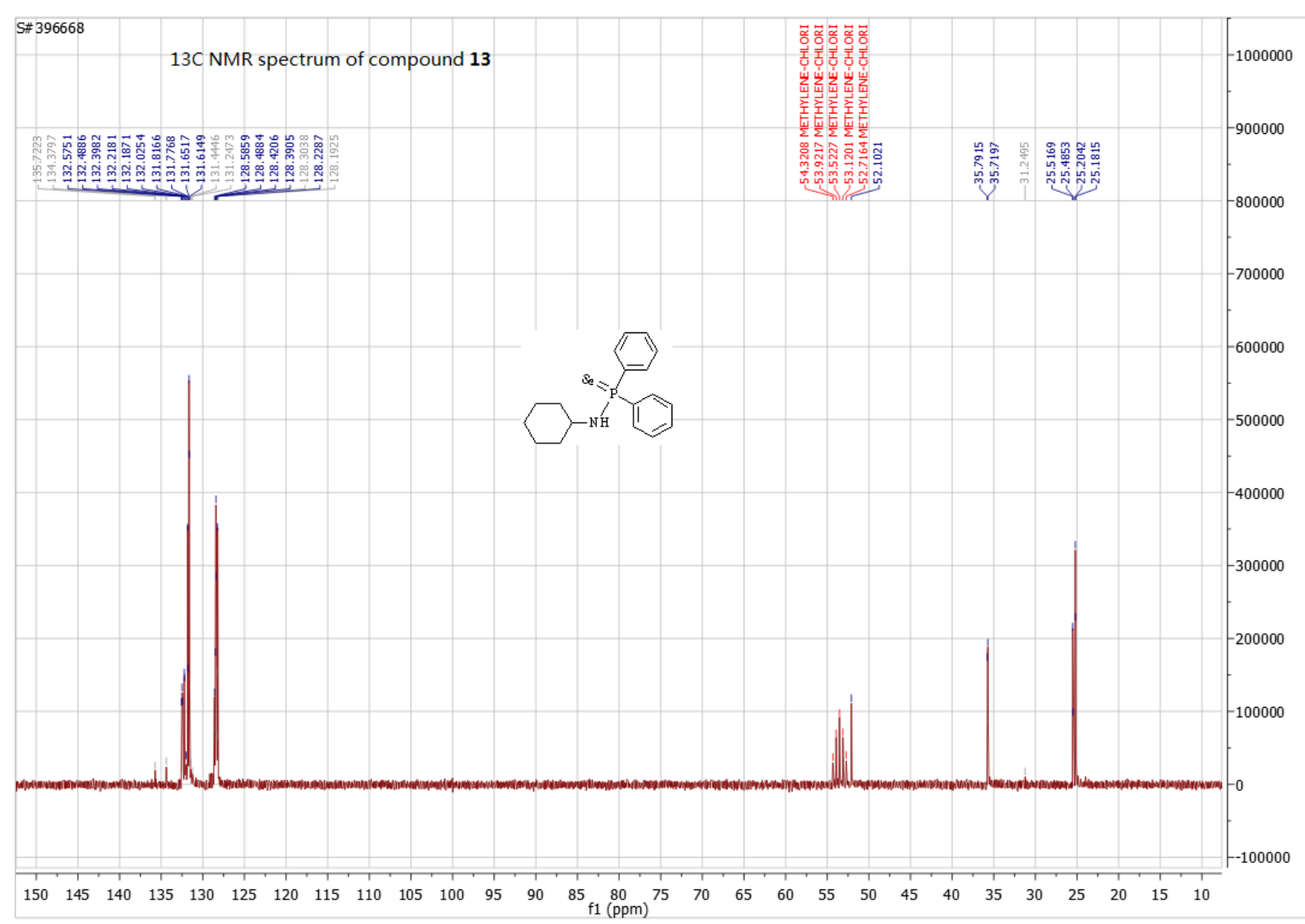


